Brazilian Journal

of Chemical

ISSN 0104-6632

Engineering

\title{
HYDRODYNAMICS OF AN EXTERNAL-LOOP AIRLIFT REACTOR WITH INSERTED MEMBRANE
}

\author{
P. S. Kojići ${ }^{*}$, S. S. Popović ${ }^{1}$, M. S. Tokić2 , I. M. Šijački ${ }^{1}$ \\ N. Lj. Lukić ${ }^{1}$, D. Z. Jovičević 1 and D. Lj. Petrović ${ }^{1}$ \\ ${ }^{1}$ Department of Chemical Engineering, Faculty of Technology, University of Novi Sad, \\ Bulevar Cara Lazara 1, 21000 Novi Sad, Serbia. \\ E-mail: kojic@tf.uns.ac.rs \\ ${ }^{2}$ Laboratory of Computational Systems Biotechnology (LCSB), Ecole Polytechnique Federale de Lausane, \\ CH 1015 Lausanne, Switzerland.
}

(Submitted: June 24, 2015; Revised: November 25, 2015; Accepted: January 15, 2016)

\begin{abstract}
The objective of this study was to investigate the hydrodynamics of an external-loop airlift membrane reactor (ELAMR). The ELAMR was operated in two modes: without (mode A) and with bubbles in the downcomer (mode B), depending on the liquid level in the gas separator. The influence of the gas distributor's geometry and various alcohol solutions on the hydrodynamics of the ELAMR was studied. Results for the gas holdup and the downcomer liquid velocity are commented with respect to an external-loop airlift reactor of the same geometry but without the membrane in the downcomer (ELAR). Due to the presence of the membrane in the downcomer, acting as the local hydrodynamic resistance, the gas holdup in the riser of the ELAMR increases maximally by $16 \%$, while the liquid velocity in the downcomer decreases up to $50 \%$. The values of the gas holdup and liquid velocity predicted by the application of empirical power law correlations and a feed forward back propagation neural network (ANN) are in very good agreement with experimental values.
\end{abstract}

Keywords: membrane air lift reactor; hydrodynamics; dilute alcohol solution; geometry of distributor; multichannel membrane.

\section{INTRODUCTION}

Over the past few decades airlift reactors have been widely used in chemical and biotechnological processes, wastewater treatment and various fermentation systems. The airlift reactors have many advantages, such as the selfgenerated liquid circulation caused by hydrostatic pressure differences, simple construction, good heat transfer, good mixing, low costs, absence of moving parts, high capacity, relatively low energy consumption and minimal space requirements. Also, they easily enable fluidization of solid particles. There are many variations of these reactors, but the two major groups are: internal loop airlift reactors (ILAR) and external-loop airlift reactors (ELAR).
The progress in waste water treatment, chemical processes and biotechnology industries requires reactors with in situ product removal. In situ separation processes recover desired product or remove harmful components from the reactor. Therefore, airlift reactors were combined with separation processes such as: liquid-liquid extraction (Gianetto et al., 1988; Yuan et al., 2001) and adsorption or ion exchange (Sun et al., 1999). Nowadays, in situ membrane separation process coupled with reactor has received considerable attention (Carstensen et al., 2012). In this integrated process, both the biomass formation and liquid separation with soluble products take place in one membrane bioreactor (MBR). This process has many advantages, such as an excellent and stable effluent

*To whom correspondence should be addressed 
quality, compact equipment, high volumetric load and less surplus sludge production (Liu et al., 2000). One of the newest types of MBRs is the airlift MBR (Futselaar et al., 2007). This reactor has lower energy consumption, compared to conventional cross-flow MBR, because it preferably uses air to control membrane fouling and to recirculate liquid (Futselaar et al., 2007). Namely, the liquid circulation is induced without a circulation pump. Therefore, in the past years different types of airlift MBR configurations have been designed and investigated. Liu et al. (2000) investigated hydrodynamics and its effect on transmembrane pressure in an internal airlift membrane bioreactor. They found that the cross flow velocities increase with an increase of the superficial gas velocity. Jajuee et al. (2006) conducted experiments in a $25 \mathrm{dm}^{3}$ three-phase concentric airlift reactor with a semipermeable membrane. They observed that the mass transfer coefficient was strongly affected by p-xylene, naphthalene and solid loadings. The effect of hydrodynamic conditions and operating modes on the permeate flux in a submerged airlift hollow fiber membrane system was studied by Bérubé and Lei (2006). Li et al. (2008) developed an innovative single stage continuously aerated internal-loop membrane airlift bioreactor for simultaneous nitrification and denitrification of synthetic domestic wastewaters. Xu and $\mathrm{Yu}(2008)$ investigated the hydrodynamics of a novel multi-airlifting membrane bioreactor, constructed with four sintered stainless steel tubular filters serving as the risers and downcomers. In several studies the hydrodynamics in a draft tube airlift reactor with and without membrane have been simulated using computational fluid dynamics software (CFD) (Moraveji et al., 2012; Prieske et al., 2008). They concluded that the presence of membrane caused an increase in the gas holdup and decreased the driving force for liquid movement. Mihal' et al. (2013) used a hybrid system consisting of an ILAR and membrane module immersed in the downcomer for in situ 2-phenylethanol removal from the fermentation medium.

In all mentioned airlift MBRs the membranes were submerged in the reactor. The key problem of this set-up is that the reactor requires small bubbles for high gas holdup and good gas-liquid mass transfer, while the membrane requires large bubbles to control membrane fouling (Cui et al., 2003; Futselaar et al., 2007). To overcome these problems, external-loop airlift membrane reactors (ELAMR) have been developed. In the ELAMR the riser acts as the reactor, while the separation takes place in the downcomer with an inserted membrane. One of the first configurations of this type of reactor was constructed by Norit for commercial application (Futselaar et al., 2007). Fan et al. (2006) successfully used an H-type recycling pipe external-loop airlift membrane bioreactor to treat and reuse municipal wastewater. Shariati et al. (2010) removed acetaminophen as the main pollutant of pharmaceutical wastewater in a rectangular ELAMR. The removal efficiency of acetaminophen was significantly higher for the ELAMR, in comparison to a conventional activated sludge laboratory system.

The hydrodynamics in an ELAMR has significance in the control of membrane fouling and maintenance of the steady operation (Liu et al., 2000). The gas holdup and the downcomer liquid velocity are the most important hydrodynamic parameters (Chisti, 1988). It is well known that gas holdup and downcomer liquid velocity in the ELAR depend on parameters such as superficial gas velocity, ratio of the downcomer to riser cross-sectional area, horizontal connector geometries, hydrodynamic resistance to the liquid flow, liquid height in the gas separator, type of gas distributor and physical properties of the liquid phase (Bello et al., 1984; Bentifraouine et al., 1997; Merchuk and Stein, 1981; Rujiruttanakul and Pavasant, 2011). A membrane module inserted in the downcomer represents hydrodynamic resistance to the liquid flow. Higher resistance in the ELAR leads to a decrease in the liquid velocity and an increase in the gas holdup (Bendjaballah et al., 1999; Cao et al., 2008; Merchuk and Stein, 1981; Pošarac, 1988; Verlaan et al., 1989; Vial et al., 2002).

The liquid height in the gas separator has an effect on the gas holdup and the downcomer liquid velocity (AlMasry, 1999). The critical level of the liquid in the gas separator prevents the gas bubbles from entering into the downcomer. If the liquid level is below the critical level, the downcomer drags in gas slugs. This situation is preferable in the ELAMR, because of a bigger shear stress in the multiphase flow and minimization of membrane fouling (Bérubé and Lei, 2006; Böhm et al., 2012; Ratkovich et al., 2009).

Physical properties of liquids also influence both the gas holdup and the liquid velocity. Alcohol solutions were used as a model liquid phase of non-coalescing organic mixtures in coal liquefaction and bioreactors (Kelkar et al., 1983). Addition of 2-propanol to an air-water system induces a behavior similar to the fermentation media used in aerobic bioprocesses (McClure et al., 2014). In bubble columns and airlift bioreactors inorganic salts, sugars and metabolic products, such as alcohols and organic acids, were present in significant quantities in the culture medium (Jamialahmadi and Müller-Steinhagen, 1992; Schügerl et al., 1977). A small amount of alcohol (below 1\%) remarkably decreased the surface tension of the aqueous solution, thus changing hydrodynamic properties of the airlift reactors. The surface tension of the dilute alcohol solution was the only physical property that differs from water (Freitas and Teixeira, 1998). In ELAR the presence of alcohols caused an increase in the gas holdup (AlMasry and Dukkan, 1997; Gharib et al., 2013; Miyahara and Nagatani, 2009; Pošarac, 1988; Weiland and Onken, 1981). Also, Weiland and Onken (1981) and Pošarac (1988) reported that the addition of alcohol in an ELAR increased the liquid velocity in the downcomer. On the contrary, Al- 
Masry and Dukkan (1997) and Miyahara and Nagatani (2009) found a marginal effect of alcohol solutions on the liquid velocity.

Gas distributor design has a major effect on the initial bubble size and, hence, on the hydrodynamics of the airlift reactor (Bendjaballah et al., 1999; Cao et al., 2008; Lin et al., 2004; Snape et al., 1995; Vial et al., 2000). Cao et al. (2008) performed the most comprehensive study about the influence of the gas distributor on the gas holdup and liquid velocity in the ELAR. They observed that the gas distributor had a noticeable effect on the gas holdup up to the superficial gas velocity of $0.25 \mathrm{~m} / \mathrm{s}$. At higher gas inputs, the distributor's influence was negligible. However, the effect of the gas distributor on the liquid velocity was evident in the range of gas velocities from $0.025 \mathrm{~m} / \mathrm{s}$ to $0.045 \mathrm{~m} / \mathrm{s}$.

In this paper, the hydrodynamics of an ELAMR with a short multichannel ceramic membrane inserted at the bottom of the downcomer was investigated. Such a configuration enables high hydrostatic head pressure, which decreases the power necessary for permeate removal. Furthermore, by changing the liquid level in the gas separator, the set of experiments were done with gas slug entrainment in the downcomer. This operation mode is useful for preventing membrane fouling. Also, the influences of the gas distributor's geometry and the addition of aliphatic alcohols on the riser gas holdup and downcomer liquid velocity of the ELAMR were studied. Also, this reactor has been designed for possible use as a high efficiency equipment for removal of organic and inorganic pollutants from wastewater.

\section{MATERIALS AND METHODS}

\section{Experimental setup}

A schematic illustration of the setup is shown in Figure 1. The cylindrical external-loop airlift reactor made of Plexiglas consisted of a riser $(54 \mathrm{~mm}$ i.d. and $2000 \mathrm{~mm}$ in height), downcomer ( $25 \mathrm{~mm}$ i.d. and $1950 \mathrm{~mm}$ in height) and rectangular gas separator $(400 \times 310 \times 300 \mathrm{~mm})$. The distance between the riser and the downcomer was 100 $\mathrm{mm}$. When the ELAMR was operated without gas bubbles in the downcomer (mode A), the unaerated liquid level in the gas separator was $4 \mathrm{~cm}$. Lowering the liquid level to 3 $\mathrm{cm}$, gas bubbles were dragged into the downcomer (mode B). The air, sparged into the riser, was used as the gas phase. Three different gas distributors were tested: single orifice (4 $\mathrm{mm}$ i.d.), perforated plate ( 7 holes of $1 \mathrm{~mm}$ i.d., triangular pitch) and sinter plate (100-160 $\mu \mathrm{m}$, average pore size 115 $\mu \mathrm{m}$, porosity $8 \%$ ). Porosity and average pore size of the sinter plate were obtained with a porosimeter (Porosimeter 2000 with Macropore Unit 120). The gas flow rates were controlled and measured by an electronic mass flow controller (model Bronkhorst High Tech F 201AV). The superficial gas velocity, based on the riser cross-sectional area, was varied in the range 0.02 to $0.22 \mathrm{~m} / \mathrm{s}$ for mode A. In mode $\mathrm{B}$, the entrainment of gas bubbles in the downcomer started at $\mathrm{U}_{\mathrm{G}}=0.15 \mathrm{~m} / \mathrm{s}$, so the investigated range of $\mathrm{U}_{\mathrm{G}}$ was 0.15 to $0.22 \mathrm{~m} / \mathrm{s}$. Two eDAQ (Australia) conductivity isoPods with miniature dip-in conductivity electrodes were used to determine downcomer liquid velocity. The tubular ceramic membrane $\left(\mathrm{ZrO}_{2} / \mathrm{TiO}_{2}\right.$, Novasep, France $) 20 \mathrm{~cm}$ in length and $2.3 \mathrm{~cm}$ in diameter, with 7 channels $(6 \mathrm{~mm}$ i.d.), was installed in the downcomer. The filtration was disabled in the membrane module since our aim was to investigate only the influence of the membrane acting as additional resistance on the hydrodynamics in the reactor. Also, it was considered that the permeate flux would not affect the hydrodynamics (Böhm et al., 2012).

\section{Gas-liquid systems}

Tap water and dilute alcohol solutions $(0.046 \mathrm{wt} \%$ ethanol, $0.011 \mathrm{wt} \% \mathrm{n}$-butanol and $0.0051 \mathrm{wt} \% \mathrm{n}$-hexanol) were used as the liquid phase. Added amounts of each alcohol correspond to their critical concentration reported by Keitel (1978). Increasing the alcohol concentration above the upper limiting concentration value, only enhances the liquid phase frothing and bubble coalescence (Camarasa et al., 1999; Freitas and Teixeira, 1998). Surface tensions of liquid phases and the surface tension gradient $\left(\mathrm{d} \sigma / \mathrm{dC}_{\mathrm{A}}\right)$ data were taken from Šijački et al. (2011).

\section{Measurement of hydrodynamic characteristics}

\section{Gas holdup}

The gas holdup values in the riser $\left(\varepsilon_{\mathrm{GR}}\right)$ and the downcomer $\left(\varepsilon_{\mathrm{GD}}\right)$ were obtained by measuring the pressures at the bottom and the top of the riser and downcomer using piezometric tubes, and calculated from the equation:

$$
\varepsilon_{G}=\frac{\Delta z}{\Delta H}
$$

In order to reduce the liquid surface fluctuations in the piezometric tubes, capillaries $(50 \mathrm{~mm}$ in length and 0.7 $\mathrm{mm}$ i.d.) were inserted at the entrance of the piezometric tubes. Therefore, the relative average error of these measurements was reduced to $\max \pm 2 \%$. This experimental method was adopted from Zahradník et al. (1974). Also, it was visually observed that the gas bubbles did not enter into the piezometric tube due to frothing in the riser and the downcomer.

\section{Liquid velocity in the downcomer}

The liquid velocity in the downcomer $\left(\mathrm{W}_{\mathrm{LD}}\right)$ was determined by the tracer response method. Two conductivity probes were placed in the downcomer section at a distance (L) of $1.4 \mathrm{~m}$ from each other. A volume of $25 \mathrm{~cm}^{3}$ of $4 \mathrm{M}$ 


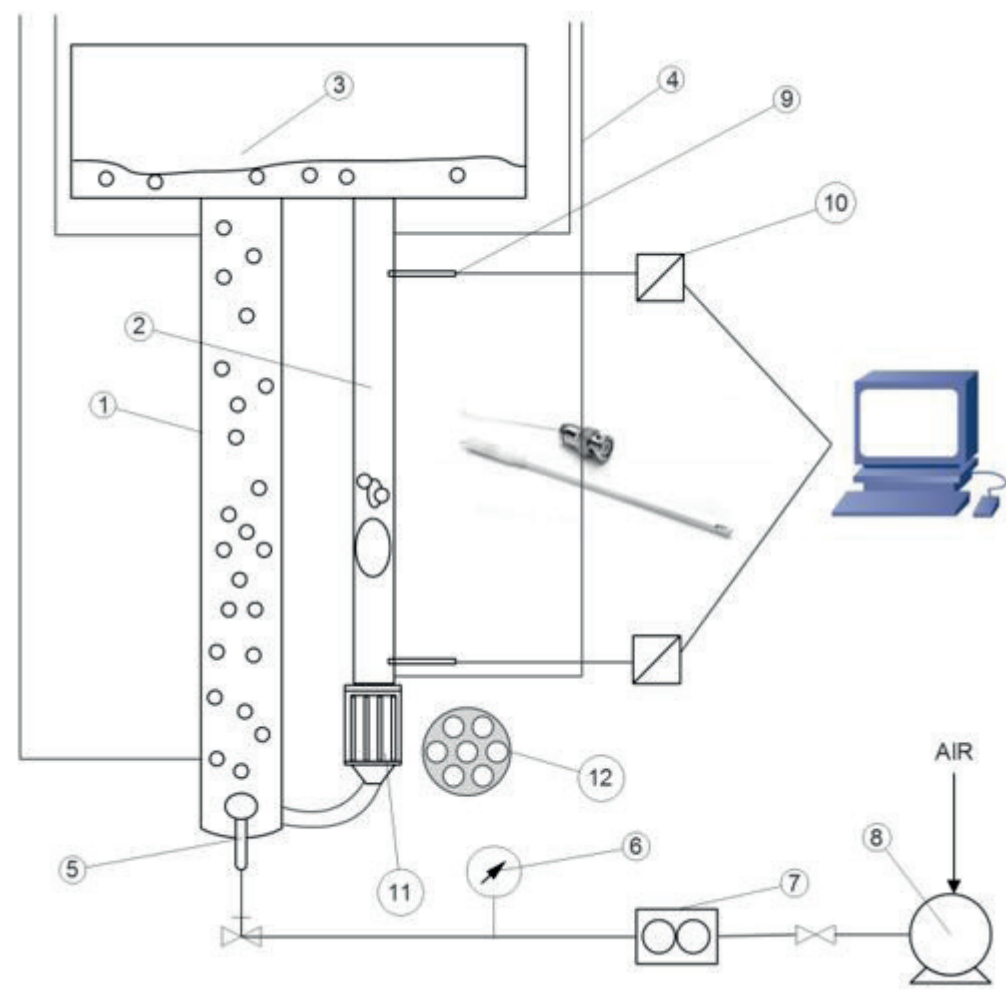

Figure 1. Experimental setup: 1-riser, 2-downcomer, 3-gas separator, 4-piezometric tubes, 5-gas distributor, 6-manometer, 7-mass flow controller, 8-air compressor, 9-conductivity electrode, 10-conductivity isopod, 11-membrane module, 12-membrane.

$\mathrm{NaCl}$, used as a tracer, was instantaneously injected $15 \mathrm{~cm}$ above the top electrode. Liquid velocity in the downcomer was calculated from the measured time interval between the tracer peaks from the two conductivity probes and the known vertical distance between them, by the following equation:

$$
W_{L D}=\frac{L}{t_{2}-t_{1}}
$$

The cross flow velocity inside the membrane could be calculated using the continuity equations by knowing $\mathrm{W}_{\mathrm{LD}}$. Signals were recorded at a frequency of $0.1 \mathrm{~s}$. For each value of a gas flow rate two measurements were performed and the average value of $\mathrm{W}_{\mathrm{LD}}$ was calculated. The relative average error of this method was $\pm 3 \%$.

\section{Friction coefficient}

To quantify the hydrodynamic resistance of the membrane itself, it was necessary to calculate the overall friction coefficient $\left(\mathrm{K}_{\mathrm{f}}\right)$ in both reactors. The $\mathrm{K}_{\mathrm{f}}$ was derived according to Verlaan (1987) by plotting the square of the measured superficial liquid velocity as a function of the difference between gas holdups in the riser and the downcomer:

$$
W_{L D}{ }^{2}=\frac{2 g H}{K_{f}}\left(\varepsilon_{G R}-\varepsilon_{G D}\right)
$$

The commercial software pipe flow expert was used to calculate $\mathrm{K}_{\mathrm{f(calc})}$. $\mathrm{K}_{\mathrm{f(calc)}}$ was estimated according to GarciaCalvo (1992) and Milivojević (2011) as the sum of specific fittings in each reactor separately. In the estimation of $\mathrm{K}_{\mathrm{f}(\mathrm{calc})}$ the fitting that represented the resistance of the membrane was taken as a partially open valve for the ELAMR and as a fully open valve for the ELAR. The assumption was made that the type of distributor and alcohol do not influence $\mathrm{K}_{\mathrm{f}(\mathrm{calc})}$. A good agreement between calculated and experimental $\mathrm{K}_{\mathrm{f}}$ values, with maximal relative error of $15 \%$, was achieved.

\section{RESULTS AND DISCUSSION}

\section{Hydrodynamic regimes}

It is well known that the hydrodynamics of a bubble column (riser of the ELAR) in the gas-liquid co-current operation mode is characterized by different flow patterns depending on the gas flow rate: homogenous (bubble flow), 
transition, heterogeneous (churn-turbulent flow) regimes and slug flow(Govier, 1972; Hatch, 1975; Wallis, 1969).

In both reactors, ELAR and ELAMR, for operating mode $\mathrm{A}$ the existence of all regimes was confirmed (Figures $2 \mathrm{ac}$ and $3 \mathrm{a}-\mathrm{c}$ ). The transition between regimes was identified by the change of the slope of the gas holdup vs. the gas velocity curves. A more detailed analysis of hydrodynamic regimes and transition superficial gas velocities was described in our earlier study (Kojić et al., 2015). The transition points in the ELAMR appeared at a slightly lower $\mathrm{U}_{\mathrm{G}}$ compared to the ELAR. This is because the larger hydrodynamic resistance in the ELAMR caused lower $\mathrm{W}_{\mathrm{LD}}$ that induced more intensive bubble coalescence. Joshi et al. (1990) and Bendjaballah et al. (1999) also noted that the resistance in the ELAR, and thereby $\mathrm{W}_{\mathrm{LD}}$, and the geometry of the downcomer influenced the regime transitions. On the other hand, Vial et al. (2002) reported that the hydrodynamic resistance had a minor influence on the regime transitions. As can be seen in Figures 2 and 3, added alcohol had a noticeable influence on the transition between regimes in both ELAR and ELAMR for the sinter plate and perforated plate. But, for a single orifice this transition was the same for all alcohol solutions. The presence of alcohols delayed the heterogeneous regime, due to their coalescence inhibiting nature (Pošarac, 1988; Weiland and Onken, 1981). The effect of the gas distributor type on the regime transition in the ELAR and ELAMR was also observed. When a single orifice was used, the absence of bubble flow was noted even at the lowest $U_{G}$. Both reactors operated instantly in the transition regime, that is in agreement with the observations of Bendjaballah et al. (1999) and Vial et al. (2001). In mode B, at $\mathrm{U}_{\mathrm{G}} \geq 0.15$ $\mathrm{m} / \mathrm{s}$, gas slugs started to be dragged into the downcomer. The length of the slugs was $\sim 5 \mathrm{~cm}$ in water and $\sim 3 \mathrm{~cm}$ in alcohol solutions. When the alcohols were added, smaller number of gas slugs were created in the downcomer, in comparison to water. Mode B is significant for the mitigation of membrane fouling. Large bubbles or slugs are more beneficial as they have larger wake regions, create stronger secondary flows and are more effective in promoting local mixing than smaller bubbles. Also, for a fixed bubble volume, an increase in bubbling frequency means more falling films and bubble wakes per unit time (Cui et al., 2003). According to Ratkovich et al. (2009) gas slugs increase the shear stress across the membrane and prevent membrane fouling.

\section{Gas Holdup}

Influence of the superficial gas velocity on the gas holdup

The influence of the superficial gas velocity on the riser gas holdup is presented in Figures 2 and 3 for the ELAR and ELAMR, respectively. For all the gas-liquid systems and both reactors (ELAR and ELAMR), the gas holdup increased with an increase in the superficial gas velocity, and it was higher in the ELAMR than in the ELAR. The increase in $\varepsilon_{\mathrm{GR}}$ was the highest for the single orifice (about $16 \%$ ), while for the perforated plate and the sinter plate it was lower (about 8\%). When the ELAMR was operated in mode $\mathrm{B}, \varepsilon_{\mathrm{GD}}$ was up to 0.03 , while $\varepsilon_{\mathrm{GR}}$ was unchanged. $\varepsilon_{\mathrm{GD}}$ values were about 10 times lower, compared to $\varepsilon_{\mathrm{GR}}$ (Figure 3).

To quantify the influence of the membrane as the resistance to the flow in the ELAMR, the overall friction coefficient was calculated from equation 3 by fitting the experimental data. The insertion of the membrane in the downcomer of our ELAR increased the overall friction coefficient by $90 \%$ while $\varepsilon_{\mathrm{GR}}$ was slightly increased. Table 1 illustrates that increasing the resistance in the downcomer of the ELAR results in an increase in $\varepsilon_{\mathrm{GR}}$. This effect is the most pronounced when the cross section of the downcomer is reduced by more than $50 \%$. Furthermore, this contributed to an increase of $\mathrm{K}_{\mathrm{f}}$ by more than $100 \%$. Reduced liquid velocity decreased the rise velocity of the bubbles and consequently increased $\varepsilon_{\mathrm{GR}}$.

\section{Influence of added alcohol on the gas holdup}

The effect of alcohols on the gas holdup in both reactors, without and with membrane, was the same (Figures 2 and 3 ). The addition of alcohols led to an increase in $\varepsilon_{\mathrm{GR}}$, in comparison to water for all distributors, but more intensively for the sinter plate (SP) and perforated plate (PP). At $\mathrm{U}_{\mathrm{G}} \leq 0.05 \mathrm{~m} / \mathrm{s}$ only slight differences in $\varepsilon_{\mathrm{GR}}$ were observed, regardless of the geometry of the distributor and type of alcohol. In the bubble flow no coalescence was observed, even in the water. However, in the transition and churn-turbulent flow $\varepsilon_{\mathrm{GR}}$ was about $22,17.5$, and $10 \%$ higher for ethanol, n-butanol and n-hexanol solutions, respectively for $\mathrm{SP}$ and $\mathrm{PP}$, in comparison to water. At high gas velocities, corresponding to the transition and heterogeneous flow, coalescence was much stronger with frequent bubble collisions. The inertial forces dominated over the surface forces and the effect of coalescence inhibition due to added alcohol was more pronounced. The effect of added alcohol on $\varepsilon_{\mathrm{GR}}$ for the single orifice (SO) (Figures 2 and 3) was lower than for the PP and the SP, so in the transition and the churn-turbulent regime alcohol solutions had only about a $7 \%$ higher $\varepsilon_{\mathrm{GR}}$ compared to water. The SO produced large bubbles and the gas-liquid system was instantly in the transition regime; therefore, it was difficult for alcohols to form monolayer around the bubbles and prevent coalescence. When the ELAMR was operated in mode $\mathrm{B}$, added alcohols slightly decreased $\varepsilon_{\mathrm{GD}}$, compared to water.

\section{Influence of distributor type on the gas holdup}

The effect of gas distributor: SO, PP and SP is shown in Figures 2 and 3. It can be clearly seen, that the SP for 
Table 1. List of the influence of hydrodynamic resistance on the riser gas holdup and downcomer liquid velocity in the external-loop airlift reactors.

\begin{tabular}{|c|c|c|c|c|}
\hline $\begin{array}{l}\text { Ref., resistance and } \\
\text { sparger type }\end{array}$ & $\begin{array}{l}\text { Valve or orifice } \\
\text { plate opening }\end{array}$ & $\begin{array}{l}\text { Friction coefficient } \\
\qquad\left(\mathbf{K}_{\mathrm{f}}\right)\end{array}$ & $\begin{array}{l}\text { The increase of } \varepsilon_{\mathrm{GR}} \\
\text { relative to a fully open } \\
\text { downcomer }(\%)\end{array}$ & $\begin{array}{c}\text { The decrease of } \mathrm{W}_{\mathrm{LD}} \text { relative to a } \\
\text { fully open downcomer }(\%)\end{array}$ \\
\hline \multirow{5}{*}{$\begin{array}{c}\text { Verlaan (1987) } \\
\text { (valve, single orifice) }\end{array}$} & \multirow{5}{*}{ lack of data } & 4.6 & - & - \\
\hline & & 8.9 & 7 & 24 \\
\hline & & 19.3 & 22 & 46 \\
\hline & & 61.5 & 42 & 68 \\
\hline & & 409 & 55 & 88 \\
\hline \multirow{4}{*}{$\begin{array}{l}\text { Pošarac (1988) } \\
\text { (orifice plate) }\end{array}$} & 100 & 15 & - & - \\
\hline & 50 & 19 & 17 & 9 \\
\hline & 30 & 35 & 38 & 26 \\
\hline & 5 & 793 & 117 & 77 \\
\hline \multirow{5}{*}{$\begin{array}{c}\text { Bendjaballah } \\
\text { et al. (1999) } \\
\text { (valve, multiple orifice) }\end{array}$} & 100 & 6.9 & - & - \\
\hline & 77 & 7.2 & 2.2 & 5.9 \\
\hline & 46 & 8.2 & 5.5 & 10.4 \\
\hline & 23 & 15.3 & 23 & 30 \\
\hline & 7 & 43.1 & 51 & 55 \\
\hline \multirow{3}{*}{$\begin{array}{l}\text { Vial et al. (2002) } \\
\text { (valve, multiple orifice) }\end{array}$} & 100 & 23 & - & - \\
\hline & 70 & 25 & 2 & 12 \\
\hline & 30 & 45 & 23 & 43 \\
\hline \multirow{3}{*}{$\begin{array}{l}\text { this paper (single orifice, } \\
\text { perforated plate and } \\
\text { sinter plate) }\end{array}$} & \multirow{3}{*}{$\begin{array}{l}\text { ELAR } \\
\text { ELAMR }\end{array}$} & $10.3-12.6$ & \multirow{3}{*}{-} & \multirow{3}{*}{$\begin{array}{l}- \\
26\end{array}$} \\
\hline & & $21.8-26.1$ & & \\
\hline & & & & \\
\hline
\end{tabular}

all used gas-liquid systems produced the highest $\varepsilon_{\mathrm{GR}}$. It is obvious that the SP and PP are more efficient distributors than the SO. The membrane module reduced the effect of the SP and PP on $\varepsilon_{\mathrm{GR}}$ in comparison to SO (by $25 \%$ to $50 \%$ depending on the gas-liquid systems). The efficiency of both the SP and PP started to decrease at lower $U_{G}$ in the ELAMR, because of the fact that the churn-turbulent flow appeared earlier than in the ELAR. The SP was more efficient than the $\operatorname{PP}\left(\mathrm{U}_{\mathrm{G}} \leq 0.09 \mathrm{~m} / \mathrm{s}\right)$ until the inertial forces started to be dominant. Therefore, at higher $\mathrm{U}_{\mathrm{G}}$ differences in $\varepsilon_{\mathrm{GR}}$ were less than $3 \%$. Alcohols improved the efficiency of the SP and PP compared to SO (which remained the least efficient distributor), especially in churn-turbulent flow. For instance, in the region of surface forces domination $\varepsilon_{\mathrm{GR}}$ was higher up to $40 \%$. However, at $\mathrm{U}_{\mathrm{G}}>0.09 \mathrm{~m} / \mathrm{s}$, when coalescence was intensive, $\varepsilon_{\mathrm{GR}}$ produced by the SP and PP was only $4 \%$ higher for water and about $20 \%$ for alcohol solutions. When the ELAMR was operated in mode B, the
SO produced slightly smaller $\varepsilon_{\mathrm{GD}}$ compared to the SP and PP.

\section{Downcomer liquid velocity \\ Influence of superficial gas velocity on the downcomer liquid velocity}

Figures 4 and 5 present the effect of $\mathrm{U}_{\mathrm{G}}$ on the liquid velocity in the downcomer for both operating modes and all distributors in the ELAR and the ELAMR, respectively. For all the gas-liquid systems $\mathrm{W}_{\mathrm{LD}}$ increased with increasing $\mathrm{U}_{\mathrm{G}}$. Insertion of a membrane module in the downcomer of the ELAR increased frictional energy losses and led to a decrease of $\mathrm{W}_{\mathrm{LD}}$ in the range of $36-49 \%$ for both SP and $\mathrm{PP}$, while for SO the decrease was in the range of $19-27 \%$, depending on the gas-liquid system. In order to reduce membrane fouling, it is very important to know the liquid velocity through the channel of the membrane (cross-flow 


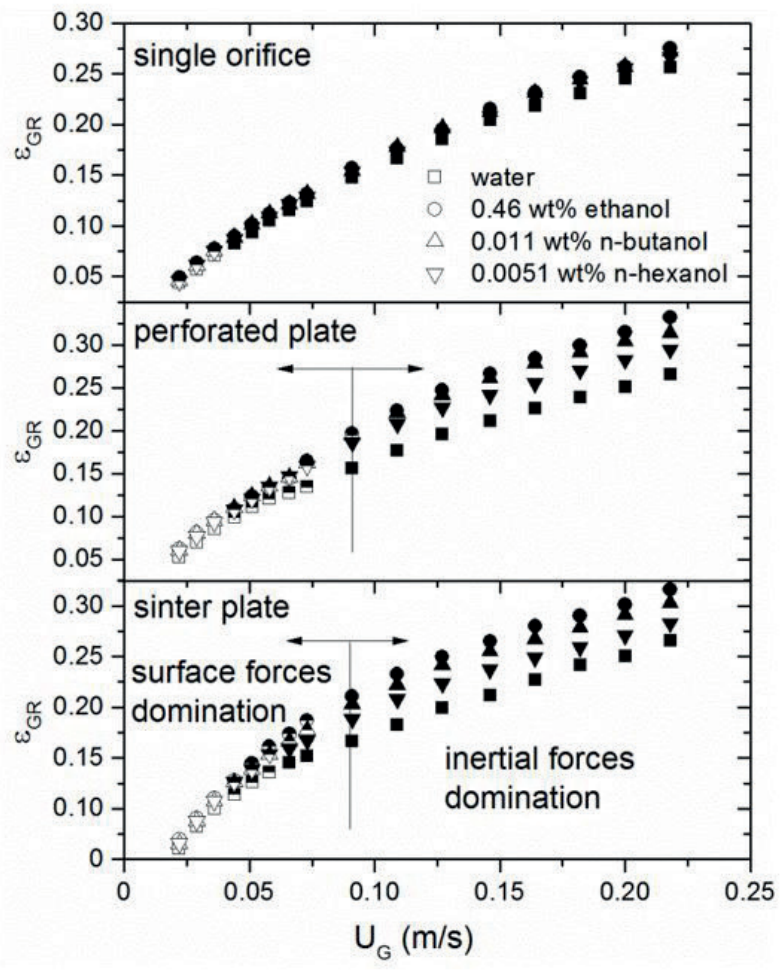

Figure 2. Influence of gas distributor type and added alcohol on the gas holdup in the ELAR. Hydrodynamic regime legend: open symbols, homogeneous regime; half solid symbols, transition regime; solid symbols, heterogeneous regime and slug flow.

velocity). A continuity equation was used for its estimation. This velocity was about 2.5 times higher than $\mathrm{W}_{\mathrm{LD}}$. Our ELAMR at higher $\mathrm{U}_{\mathrm{G}}$ can achieve the cross flow velocity for microfiltration and ultrafiltration $(2-3 \mathrm{~m} / \mathrm{s})$, which was proposed by Rossignol et al. (1999) and Choi et al. (2005). When the ELAMR was operated in mode B, the slugs in the downcomer reduced $\mathrm{W}_{\mathrm{LD}}$ by $5-15 \%$, depending on the gas-liquid system and type of gas distributor. The velocities of the gas slugs in the downcomer were $35-46 \mathrm{~cm} / \mathrm{s}$, in the range of applied $\mathrm{U}_{\mathrm{G}}$.

\section{Influence of added alcohol on the downcomer liquid velocity}

The results in Figures 4 and 5 showed that the downcomer liquid velocity in the majority of the investigated gas-liquid systems and gas distributors changed with added alcohol. The reason for this is a higher driving force for the liquid circulation. Namely, the driving force is proportional to the hydrostatic pressure difference between the two vertical columns in the ELAR. Added alcohol increased the riser gas holdup, while the downcomer gas holdup remained unchanged because there

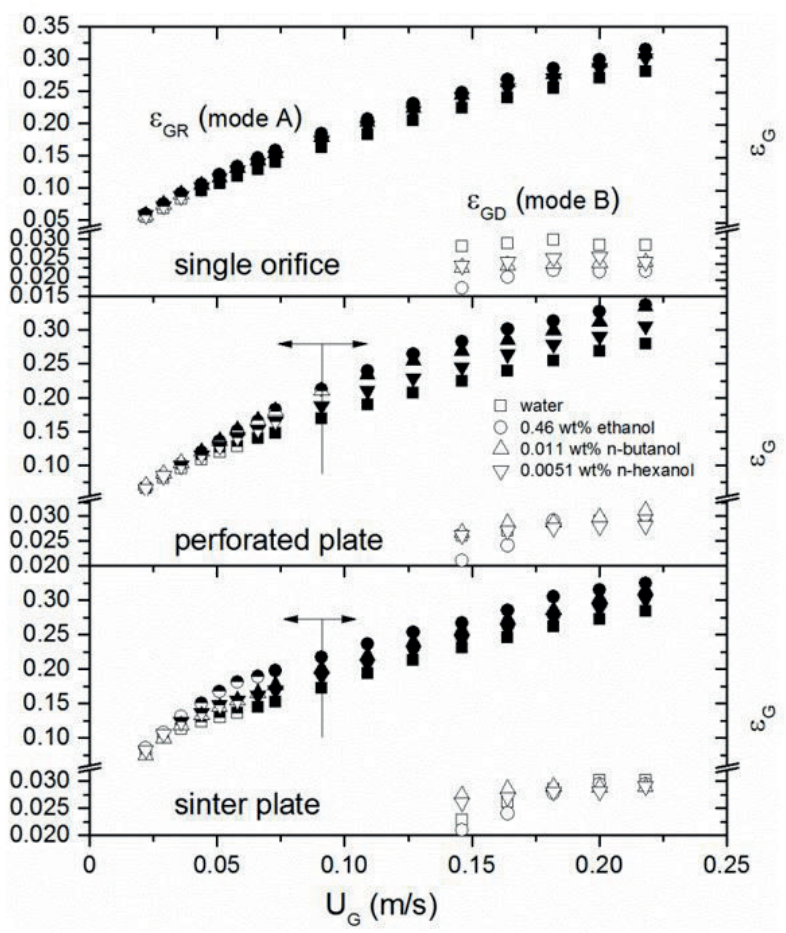

Figure 3. Influence of gas distributor type, operation mode and added alcohol on the gas holdup in the ELAMR. Hydrodynamic regime legend: open symbols, homogeneous regime; half solid symbols, transition regime; solid symbols, heterogeneous regime and slug flow.

was no bubble entrainment in the downcomer (mode A). Therefore, $\mathrm{W}_{\mathrm{LD}}$ was highest in the ethanol and n-butanol solutions for all distributors. The membrane, inserted in the downcomer of the ELAR, diminished the effect of alcohol on $\mathrm{W}_{\mathrm{LD}}$. For instance, added alcohols increased $\mathrm{W}_{\mathrm{LD}}$ from $10 \%$ to $15.5 \%$ in comparison to water in the ELAR with SP, while in the ELAMR the increase was only $3.7 \%$ to $10 \%$, depending on the alcohol solution. In both operating modes, the effect of added alcohols on $\mathrm{W}_{\mathrm{LD}}$ was the same.

\section{Influence of gas distributor on the downcomer liquid velocity}

Figures 4 and 5 show the effect of $U_{G}$ and gas distributor type on $\mathrm{W}_{\mathrm{LD}}$. In the ELAR, SP and PP were equally efficient. They gave higher $\mathrm{W}_{\mathrm{LD}}$ (12-20\% depending on the gas-liquid system) than SO. In the ELAMR the effect of gas distributor type was reduced because of more intensive coalescence that appeared at lower $\mathrm{U}_{\mathrm{G}}$ compared to the ELAR. In the region of surface forces domination (bubble and transition flow) in the ELAMR the highest $\mathrm{W}_{\mathrm{LD}}$ were achieved using SP, while the lowest ones were with SO. However, in churn-turbulent flow $\left(\mathrm{U}_{\mathrm{G}}>0.09 \mathrm{~m} / \mathrm{s}\right)$, when 


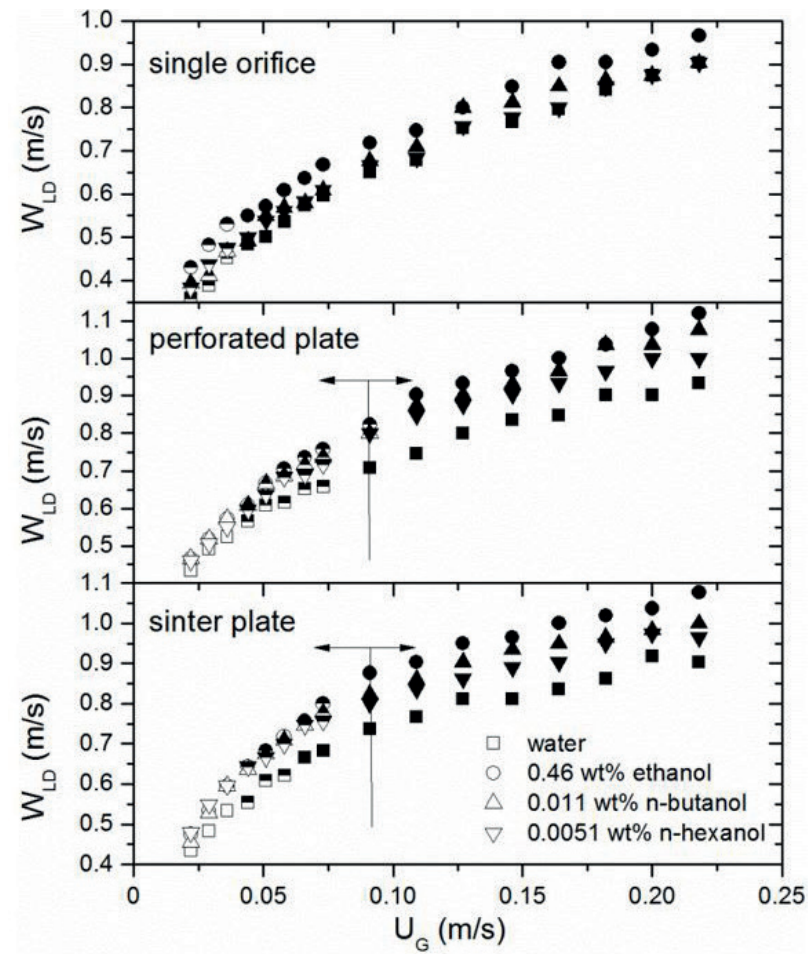

Figure 4. Influence of gas distributor type and added alcohol on the downcomer liquid velocity in the ELAR. Hydrodynamic regime legend: open symbols, homogeneous regime; half solid symbols, transition regime; solid symbols, heterogeneous regime and slug flow.

inertial forces dominated, $\mathrm{W}_{\mathrm{LD}}$ tended to be equal for all three distributors, as the differences in the $\mathrm{W}_{\mathrm{LD}}$ between distributors were less than $3 \%$. In both operating modes, the same influence of the gas distributor on $\mathrm{W}_{\mathrm{LD}}$ was noticed.

\section{CORRELATIONS}

\section{Empirical power law correlations}

According to experimental results in both operating modes examined the general comment is that $\varepsilon_{\mathrm{GR}}$ and $\mathrm{W}_{\mathrm{LD}}$ in the ELAR and ELAMR depend on the superficial gas velocity, distributor type, surface properties of the gasliquid system and overall friction coefficient. Distributor type has a strong influence on the primary bubble dispersion and therefore on the global hydrodynamics. The main parameter that describes the gas distributor, i.e., initial bubble size, is the orifice diameter $\left(\mathrm{d}_{\mathrm{o}}\right)$ (Šijački et al., 2011). The influence of alcohols on $\varepsilon_{\mathrm{GR}}$ and subsequently on $\mathrm{W}_{\mathrm{LD}}$, should be linked to changes in the surface tension gradient, i.e., to the coalescence suppression strength of

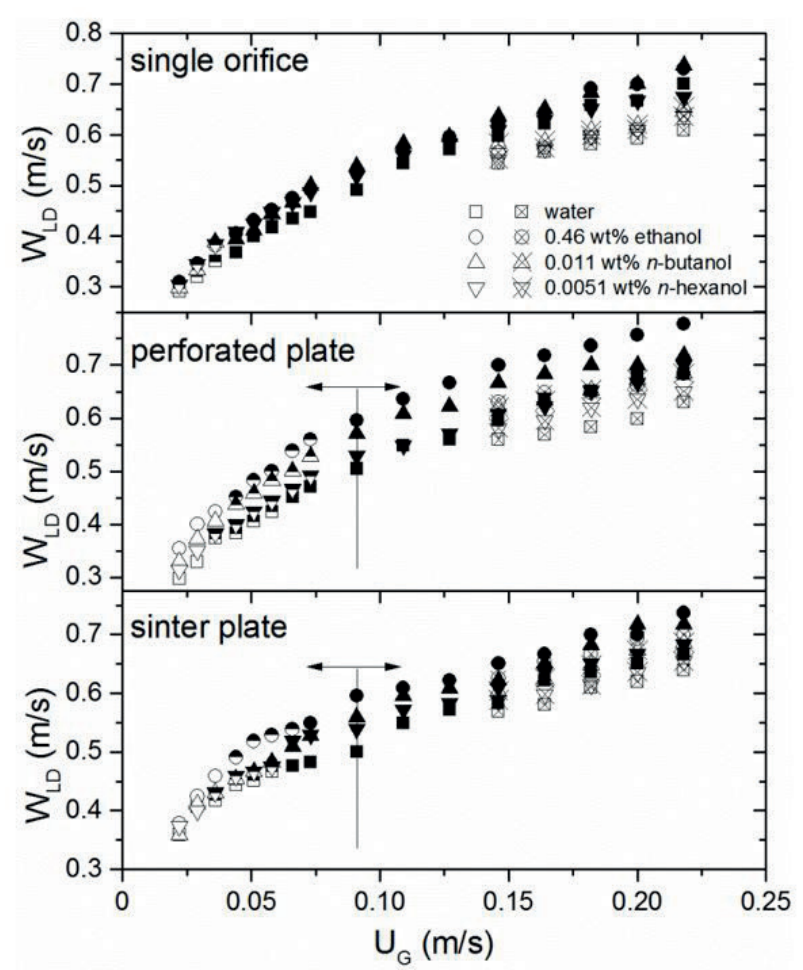

Figure 5. Influence of gas distributor type and added alcohol on the downcomer liquid velocity in the ELAMR. Hydrodynamic regime legend: open symbols, homogeneous regime; half solid symbols, transition regime; solid symbols, heterogeneous regime and slug flow; crossed open symbols, operation mode B.

individual alcohols (Albijanić et al., 2007; Camarasa et al., 1999). The effect of hydrodynamic resistance on the liquid velocity in the downcomer depends on the friction coefficient $\left(\mathrm{K}_{\mathrm{f}}\right)$ in the ELAR and ELAMR, in both operating modes. Therefore, the general form of the correlations we applied was:

$$
(\mathrm{y})_{\text {calc }}=\mathrm{AU}_{\mathrm{G}}{ }^{\mathrm{B}}\left(1+\left(-\frac{\mathrm{d} \sigma}{\mathrm{dC}}\right)\right)^{\mathrm{C}} \mathrm{d}_{\mathrm{o}} \mathrm{D}_{\mathrm{K}_{\mathrm{f}(\text { calc })}}{ }^{\mathrm{E}}
$$

The correlations were fitted for the following ranges of independent variables: $0.022<\mathrm{U}_{\mathrm{G}}<0.218 \mathrm{~m} / \mathrm{s}, 0.027<(\mathrm{d} \sigma /$ $\left.\mathrm{dC}_{\mathrm{A}}\right)<1.985 \mathrm{mNm}^{2} / \mathrm{mol}, 0.115<\mathrm{d}_{\mathrm{o}}<4 \mathrm{~mm}, 9<\mathrm{K}_{\mathrm{f}(\text { calc })}<$ 30. The coefficients were determined by minimizing the least-square sums over nonlinear correlations. These calculations were performed in Mathcad software. Table 2 contains the values of estimated parameters in the proposed correlations (eq. 4) and the goodness of fit. The parity plot of calculated values versus experimental ones is presented in Figure 6. 
Table 2. Values of correlations parameters for the riser gas holdup and downcomer liquid velocity and fit statistics

\begin{tabular}{|c|c|c|c|c|c|}
\hline $\mathrm{y}_{\text {cal }}$ (eq. 4) & $\mathbf{A}$ & B & $\mathrm{C}$ & D & $\mathbf{E}$ \\
\hline$\varepsilon_{\mathrm{GR}}$ & 0.64 & 0.61 & -0.01 & -0.02 & 0.06 \\
\hline $\mathrm{W}_{\mathrm{LD}}$ & 3.85 & 0.34 & -0.01 & -0.03 & -0.38 \\
\hline \multirow{2}{*}{ Fit statistics } & \multicolumn{2}{|c|}{ Correlation } & \multicolumn{3}{|c|}{ Artificial neural network } \\
\hline & $\varepsilon_{\mathrm{GR}}$ & $\mathrm{W}_{\mathrm{ID}}$ & $\varepsilon_{\mathrm{GR}}$ & & \\
\hline mean relative errors $(\%)$ & 8.8 & 5.8 & 5 & & \\
\hline coefficient of determination & 0.95 & 0.93 & 0.97 & & \\
\hline mean absolute errors & 0.37 & 0.96 & 0.27 & & \\
\hline root mean square errors & 0.018 & 0.045 & 0.013 & & \\
\hline
\end{tabular}

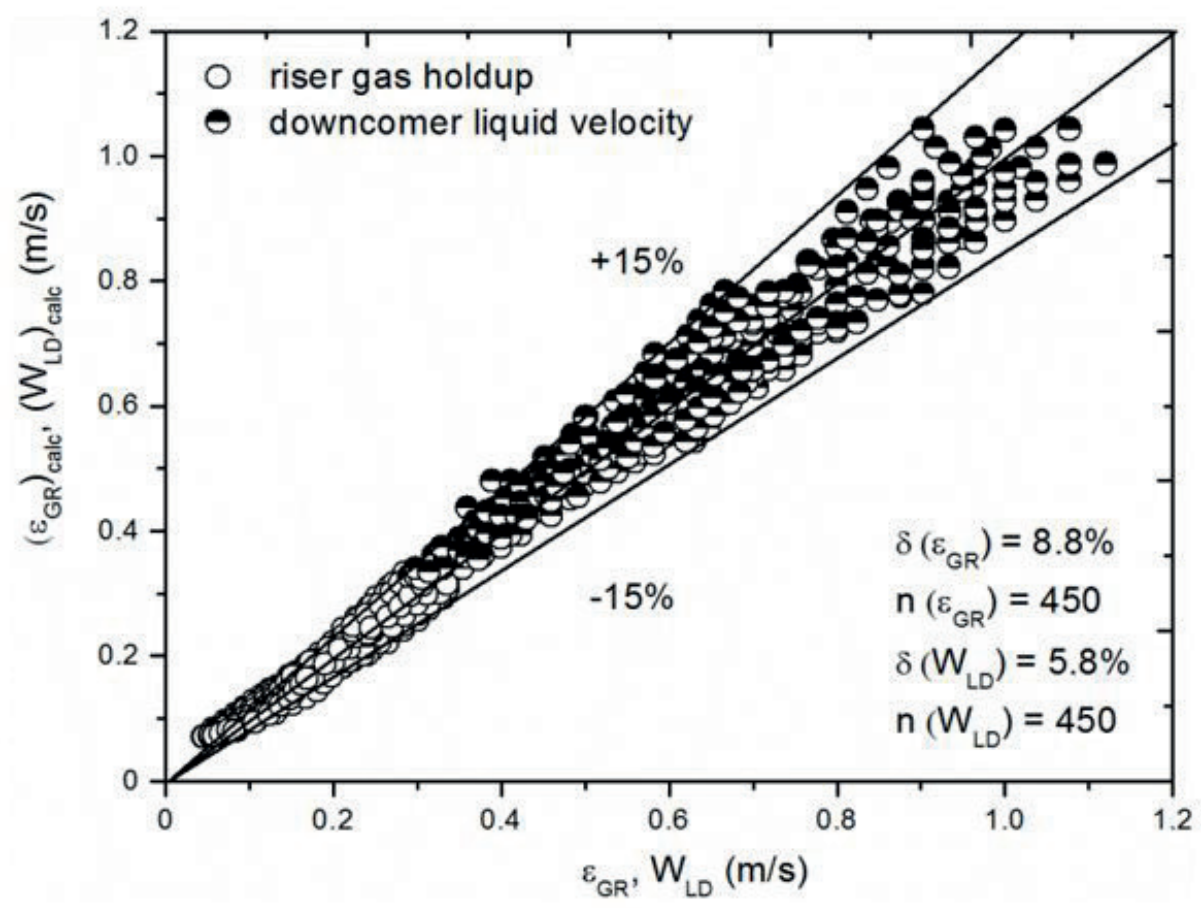

Figure 6. Comparison of experimental and predicted values for the riser gas holdup and downcomer liquid velocity using the proposed correlations (4).

\section{Neural network simulations}

In this study the feed-forward artificial neural network model (ANN) was used, beside the previously proposed empirical power law correlations, to predict $\varepsilon_{\mathrm{GR}}$ and $\mathrm{W}_{\mathrm{LD}}$. Al-Masry (2006), and Chen et al. (2013) pointed out that an ANN reasonably predicted experimental values for liquid velocities, gas holdup and volumetric gas-liquid mass transfer coefficient in the ELAR. Neural network inputs were $\mathrm{U}_{\mathrm{G}},-\mathrm{d \sigma} / \mathrm{dC}_{\mathrm{A}}, \mathrm{d}_{\mathrm{o}}$ and $\mathrm{K}_{\mathrm{f}(\mathrm{calc})}$, the ranges of network inputs were the same as in the correlations (eq. 4) mentioned above. The number of neurons was 20 and 2 in the hidden and output layer, respectively. The network was trained with the Levenberg-Marquard back propagations algorithm. The transfer function was the logsigmoid. All 450 data points were used to train and develop the ANN: $70 \%$ of the data points for training, $15 \%$ of the data for validations and $15 \%$ of the data for the testing of the process. Figure 7 shows the parity plot of the experimental and predicted values for $\varepsilon_{\mathrm{GR}}$ and $\mathrm{W}_{\mathrm{LD}}$ using the ANN on the whole database. The statistical analysis of prediction with the ANN is shown in Table 2. Based on Table 2, the ANN predicts the experimental results more accurately than power law correlations. 


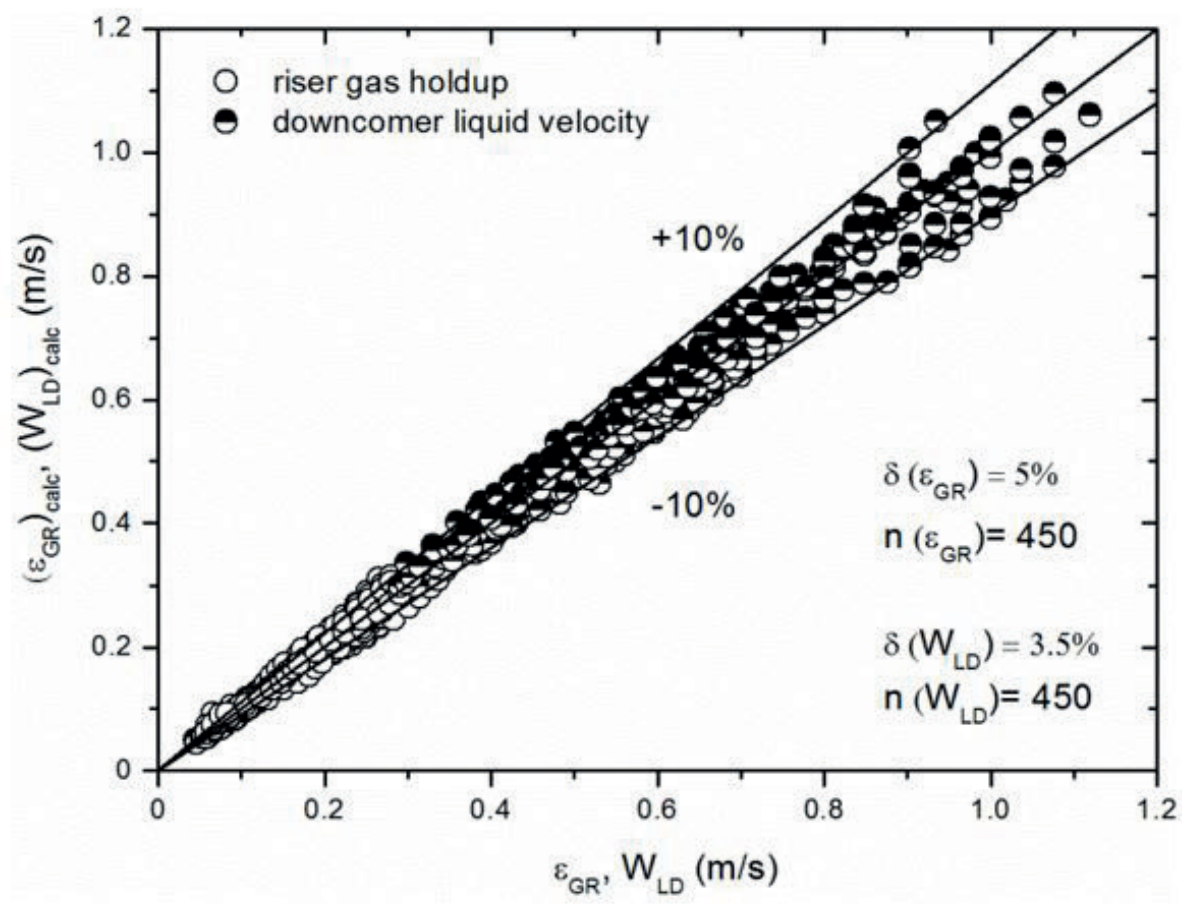

Figure 7. Comparison of experimental and predicted values for the riser gas holdup and downcomer liquid velocity using an artificial neural network.

\section{CONCLUSION}

The following conclusions could be drawn from the present study for both external-loop airlift reactors, with and without inserted membrane in the downcomer:

The insertion of the membrane in the downcomer caused a rise of the overall friction coefficient by $90 \%$ and a decrease of the downcomer liquid velocity up to $50 \%$. However, the cross-flow velocity remained in the recommended range of velocities for ultrafiltration and microfiltration given in the literature. Decreased downcomer liquid velocity resulted in up to a $16 \%$ increase of the gas holdup, while the regime transitions shifted toward the lower superficial gas velocities. The presence of bubbles in the downcomer decreased the downcomer liquid velocity up to $15 \%$ and resulted in a downcomer gas holdup up to 0.03 . An artificial neural network gave a good prediction of riser gas holdup and downcomer liquid velocity for both reactor configurations studied. Future research should be oriented toward enabling filtration within an external-loop airlift reactor with membrane in the downcomer.

\section{ACKNOWLEDGMENT}

This research was supported by the Ministry of Education and Science of the Republic of Serbia. (Project No. 172025).

\section{NOMENCLATURE}

$\mathrm{d}_{\mathrm{o}} \quad$ diameter of orifice $(\mathrm{mm})$

g gravitational acceleration rate $\left(\mathrm{m} / \mathrm{s}^{2}\right)$

$\mathrm{H} \quad$ column height (m)

$\mathrm{K}_{\mathrm{f}} \quad$ friction coefficient

L distance between conductivity electrodes (m)

t time (s)

$\mathrm{U}_{\mathrm{G}} \quad$ superficial gas velocity $(\mathrm{m} / \mathrm{s})$

$\mathrm{W}_{\mathrm{LD}}$ downcomer liquid velocity $(\mathrm{m} / \mathrm{s})$

\section{Greek letters}

$\Delta \mathrm{H}$ distance between two measuring points $(\mathrm{mm})$

$\Delta \mathrm{z}$ pressure drop between two measuring points ( $\mathrm{mm}$ )

$\delta \quad$ mean relative error (\%)

$\varepsilon_{\mathrm{GR}} \quad$ riser gas holdup

$\varepsilon_{\mathrm{GD}} \quad$ downcomer gas holdup

$-\mathrm{d} \sigma / \mathrm{dC}_{\mathrm{A}}$ surface tension gradient $\left(\mathrm{N} \mathrm{m}^{2} / \mathrm{mol}\right)$

\section{Abbreviations}

ANN artificial neural network

ELAR external-loop airlift reactor

ELAMR external-loop airlift membrane reactor

MBR membrane bioreactor 


\section{REFERENCES}

Al-Masry, W. A., Analysis of Hydrodynamics of External Loop Circulating Bubble Columns with Open Channel Gas Separators Using Neural Networks. Chem. Eng. Res. Des., 84, 483-486 (2006).

Al-Masry, W. A., Effect of liquid volume in the gasseparator on the hydrodynamics of airlift reactors. J. Chem. Technol. Biotechnol., 74, 931-936 (1999).

Al-Masry, W. A., Dukkan, A. R., The role of gas disengagement and surface active agents on hydrodynamic and mass transfer characteristics of airlift reactors. Chem. Eng. J., 65, 263-271 (1997).

Albijanić, B., Havran, V., Petrović, D. L., Đurić, M., Tekić, M. N., Hydrodynamics and mass transfer in a draft tube airlift reactor with dilute alcohol solutions. AlChE J., 53, 2897-2904 (2007).

Bello, R. A., Robinson, C. W., Moo-Young, M., Liquid circulation and mixing characteristics of airlift contactors. Can. J. Chem. Eng., 62, 573-577 (1984).

Bendjaballah, N., Dhaouadi, H., Poncin, S., Midoux, N., Hornut, J. M., Wild, G., Hydrodynamics and flow regimes in external loop airlift reactors. Chem. Eng. Sci., 54, 5211-5221 (1999).

Bentifraouine, C., Xuereb, C., Riba, J.-P., An Experimental Study of the Hydrodynamic Characteristics of External Loop Airlift Contactors. J. Chem. Technol. Biotechnol., 69, 345-349 (1997).

Bérubé, P. R., Lei, E., The effect of hydrodynamic conditions and system configurations on the permeate flux in a submerged hollow fiber membrane system. J. Membr. Sci., 271, 29-37 (2006).

Böhm, L., Drews, A., Prieske, H., Bérubé, P. R., Kraume, M., The importance of fluid dynamics for MBR fouling mitigation. Bioresour. Technol., 122, 50-61 (2012).

Camarasa, E., Vial, C., Poncin, S., Wild, G., Midoux, N., Bouillard, J., Influence of coalescence behaviour of the liquid and of gas sparging on hydrodynamics and bubble characteristics in a bubble column. Chem. Eng. Process., 38, 329-344 (1999).

Cao, C., Dong, S., Geng, Q., Guo, Q., Hydrodynamics and Axial Dispersion in a Gas-Liquid-(Solid) EL-ALR with Different Sparger Designs. Ind. Eng. Chem. Res., 47, 4008-4017 (2008).

Carstensen, F., Apel, A., Wessling, M., In situ product recovery: Submerged membranes vs. external loop membranes. J. Membr. Sci., 394-395, 1-36 (2012).

Chen, Z., Liu, H., Zhang, H., Ying, W., Fang, D., Oxygen mass transfer coefficient in bubble column slurry reactor with ultrafine suspended particles and neural network prediction. Can. J. Chem. Eng., 91, 532-541 (2013).
Chisti, M. Y., Airlift bioreactors. Elsevier Applied Science, London (1988).

Choi, H., Zhang, K., Dionysiou, D. D., Oerther, D. B., Sorial, G. A., Influence of cross-flow velocity on membrane performance during filtration of biological suspension. J. Membr. Sci., 248, 189-199 (2005).

Cui, Z. F., Chang, S., Fane, A. G., The use of gas bubbling to enhance membrane processes. J. Membr. Sci., 221, $1-35$ (2003).

Fan, Y., Li, G., Wu, L., Yang, W., Dong, C., Xu, H., Fan, W., Treatment and reuse of toilet wastewater by an airlift external circulation membrane bioreactor. Process Biochem., 41, 1364-1370 (2006).

Freitas, C., Teixeira, J. A., Effect of liquid-phase surface tension on hydrodynamics of a three-phase airlift reactor with an enlarged degassing zone. Bioprocess. Eng., 19, 451-457 (1998).

Futselaar, H., Schonewille, H., de Vente, D., Broens, L., NORIT AirLift MBR: side-stream system for municipal waste water treatment. Desalination, 204, 1-7 (2007).

Garcia-Calvo, E., Fluid dynamics of airlift reactors: Twophase friction factors. AIChE J., 38, 1662-1666 (1992).

Gharib, J., Keshavarz Moraveji, M., Davarnejad, R., Malool, M. E., Hydrodynamics and mass transfer study of aliphatic alcohols in airlift reactors. Chem. Eng. Res. Des., 91, 925-932 (2013).

Gianetto, A., Ruggeri, B., Specchia, V., Sassi, G., Forna, R., Continuous extraction loop reactor (CELR): Alcoholic fermentation by fluidized entrapped biomass. Chem. Eng. Sci., 43, 1891-1896 (1988).

Govier, G. W. A. K., The flow of complex mixtures in pipes. Van Nostrand Reinhold Co., New York (1972).

Hatch, R. T., Fermenter design, in: Single Cell Protein II (S. R. Tannenbaum and D. I. C. Wang, eds.). MIT Press, Cambridge (1975); p 46-68.

Jajuee, B., Margaritis, A., Karamanev, D., Bergougnou, M. A., Mass transfer characteristics of a novel three-phase airlift contactor with a semipermeable membrane. Chem. Eng. J., 125, 119-126 (2006).

Jamialahmadi, M., Müller-Steinhagen, H., Effect of alcohol, organic acid and potassium chloride concentration on bubble size, bubble rise velocity and gas hold-up in bubble columns. Chem. Eng. J., 50, 47-56 (1992).

Joshi, J. B., Ranade, V. V., Gharat, S. D., Lele, S. S., Sparged loop reactors. Can. J. Chem. Eng., 68, 705741 (1990).

Keitel, G. Untersuchungen zum Stoffaustausch in GasFlüssig-Dispersionen in Rührschlaufenreaktor und Blasensäule. PhD Thesis, Universität Dortmund, Dortmund, Germany (1978).

Kelkar, B. G., Godbole, S. P., Honath, M. F., Shah, Y. T., Carr, N. L., Deckwer, W. D., Effect of addition 
of alcohols on gas holdup and backmixing in bubble columns. AIChE J., 29, 361-369 (1983).

Kojić, P. S., Tokić, M. S., Šijački, I. M., Lukić, N. L., Petrović, D. L., Jovičević, D. Z., Popović, S. S., Influence of the Sparger Type and Added Alcohol on the Gas Holdup of an External-Loop Airlift Reactor. Chem. Eng. Technol., 38, 701-708 (2015).

Li, Y. Z., He, Y. L., Ohandja, D. G., Ji, J., Li, J. F., Zhou, T., Simultaneous nitrification-denitrification achieved by an innovative internal-loop airlift MBR: Comparative study. Bioresour. Technol., 99, 5867-5872 (2008).

Lin, J., Han, M., Wang, T., Zhang, T., Wang, J., Jin, Y., Influence of the gas distributor on the local hydrodynamic behavior of an external loop airlift reactor. Chem. Eng. J., 102, 51-59 (2004).

Liu, R., Huang, X., Wang, C., Chen, L., Qian, Y., Study on hydraulic characteristics in a submerged membrane bioreactor process. Process Biochem., 36, 249-254 (2000).

McClure, D. D., Deligny, J., Kavanagh, J. M., Fletcher, D. F., Barton, G. W., Impact of Surfactant Chemistry on Bubble Column Systems. Chem. Eng. Technol., 37, 652-658 (2014).

Merchuk, J. C., Stein, Y., Local hold-up and liquid velocity in air-lift reactors. AIChE J., 27, 377-388 (1981).

Mihal', M., Gavin, S., Markoš, J., Airlift reactor membrane extraction hybrid system for aroma production. Chemical Papers, 67, 1485-1494 (2013).

Milivojević, M. Brzina tečnosti u dvofaznim i trofaznim pneumatskim reaktorima sa spoljašnjom cirkulacijom. PhD Thesis, University of Belgrade, Belgrade, Serbia (2011).

Miyahara, T., Nagatani, N., Influence of Alcohol Addition on Liquid-Phase Volumetric Mass Transfer Coefficient in an External-Loop Airlift Reactor with a Porous Plate. J. Chem. Eng. Jpn., 42, 713-719 (2009).

Moraveji, M. K., Sajjadi, B., Davarnejad, R., CFD Simulation of hold-up and liquid circulation velocity in a membrane airlift reactor. Theor. Found. Chem. Eng., 46, 266-273 (2012).

Pošarac, D. Investigation of hydrodynamics and masstransfer in a three phase external-loop airlift reactor. PhD Thesis, University of Novi Sad, Novi Sad, Serbia (1988).

Prieske, H., Drews, A., Kraume, M., Prediction of the circulation velocity in a membrane bioreactor. Desalination, 231, 219-226 (2008).

Ratkovich, N., Chan, C. C. V., Berube, P. R., Nopens, I., Experimental study and CFD modelling of a two-phase slug flow for an airlift tubular membrane. Chem. Eng. Sci., 64, 3576-3584 (2009).

Rossignol, N., Vandanjon, L., Jaouen, P., Quéméneur, F.,
Membrane technology for the continuous separation microalgae/culture medium: compared performances of cross-flow microfiltration and ultrafiltration. Aquacult. Eng., 20, 191-208 (1999).

Rujiruttanakul, Y., Pavasant, P., Influence of configuration on the performance of external loop airlift contactors. Chem. Eng. Res. Des., 89, 2254-2261 (2011).

Schügerl, K., Lücke, J., Oels, U., Bubble column bioreactors. In Advances in Biochemical Engineering, Volume 7, Springer Berlin Heidelberg: 1977; Vol. 7, pp 1-84.

Shariati, F. P., Mehrnia, M. R., Salmasi, B. M., Heran, M., Wisniewski, C., Sarrafzadeh, M. H., Membrane bioreactor for treatment of pharmaceutical wastewater containing acetaminophen. Desalination, 250, 798-800 (2010).

Šijački, I. M., Tokić, M. S., Kojić, P. S., Petrović, D. L., Tekić, M. N., Djurić, M. S., Milovančev, S. S., Sparger Type Influence on the Hydrodynamics of the Draft Tube Airlift Reactor with Diluted Alcohol Solutions. Ind. Eng. Chem. Res., 50, 3580-3591 (2011).

Snape, J. B., Zahradník, J., Fialová, M., Thomas, N. H., Liquid-phase properties and sparger design effects in an external-loop airlift reactor. Chem. Eng. Sci., 50, 3175-3186 (1995).

Sun, Y., Li, Y. L., Bai, S., Hu, Z. D., Modeling and Simulation of an In Situ Product Removal Process for Lactic Acid Production in an Airlift Bioreactor. Ind. Eng. Chem. Res., 38, 3290-3295 (1999).

Verlaan, P. Modelling and characterization of an airliftloop bioreactor. PhD Thesis, Wageningen University, Wageningen, Netherlands (1987).

Verlaan, P., Vos, J.-C., Van T Riet, K., Hydrodynamics of the flow transition from a bubble column to an airliftloop reactor. J. Chem. Technol. Biotechnol., 45, 109121 (1989).

Vial, C., Camarasa, E., Poncin, S., Wild, G., Midoux, N., Bouillard, J., Study of hydrodynamic behaviour in bubble columns and external loop airlift reactors through analysis of pressure fluctuations. Chem. Eng. Sci., 55, 2957-2973 (2000).

Vial, C., Poncin, S., Wild, G., Midoux, N., Experimental and theoretical analysis of the hydrodynamics in the riser of an external loop airlift reactor. Chem. Eng. Sci., 57, 4745-4762 (2002).

Vial, C., Poncin, S., Wild, G., Midoux, N., A simple method for regime identification and flow characterisation in bubble columns and airlift reactors. Chem. Eng. Process., 40, 135-151 (2001).

Wallis, G. B., One-dimensional two-phase flow. McGrawHill, New York (1969).

Weiland, P., Onken, U., Fluid Dynamics and Mass Transfer 
in an Airlift Fermenter with External Loop. Ger.Chem. Eng., 4, $42-50$ (1981).

$\mathrm{Xu}, \mathrm{Z}$., Yu, J., Hydrodynamics and mass transfer in a novel multi-airlifting membrane bioreactor. Chem. Eng. Sci., 63, 1941-1949 (2008).

Yuan, Y.-J., Wei, Z.-J., Wu, Z.-L., Wu, J.-C., Improved Taxol production in suspension cultures of Taxus chinensis var. mairei by in situ extraction combined with precursor feeding and additional carbon source introduction in an airlift loop reactor. Biotechnol. Lett, 23, 1659-1662 (2001).

Zahradník, J., Kaštánek, F., Rylek, M., Porosity of the heterogeneous bed and liquid circulation in multistage bubble-type column reactors. Collect. Czech. Chem. Commun., 39, 1403-1418 (1974). 